\title{
Marfan syndrome: fibrillin expression and microfibrillar abnormalities in a family with predominant ocular defects
}

\author{
Cay M Kielty, Sally J Davies, Janet E Phillips, Carolyn J P Jones, \\ C Adrian Shuttleworth, Stephen J Charles
}

\begin{abstract}
We have found abnormal fibrillin microfibrils isolated from tissues and cell cultures from two cousins with Marfan syndrome whose major clinical abnormality is bilateral ectopia lentis, but who also have skeletal involvement but no cardiovascular defects. Ultrastructural analysis of ciliary zonules showed the presence of abundant loose microfibril bundles which in many places appeared disorganised. Microfibrils isolated from ciliary zonules and vitreous were highly fragmented when examined by rotary shadowing electron microscopy. Investigation of microfibrils elaborated by patient dermal fibroblasts showed remarkable variations in periodicity and packing. The synthesis and secretion of fibrillin by these cells was confirmed electrophoretically with the identification of metabolically labelled immunoprecipitated fibrillin $\left(M_{r} 300000\right)$ in medium and cell layer compartments. These data show that fibrillin expression is normal but that assembled microfibrils are manifestly abnormal both morphologically and functionally. The occurrence of microfibrils with variable periodicities and susceptibility to fragmentation suggests that structural weakness is probably the primary cause of lens dislocation in these patients.
\end{abstract}

( $($ Med Genet 1995;32:1-6)

Mutations in the FBN1 gene that encodes the glycoprotein fibrillin are responsible for Marfan syndrome, an autosomal dominant connective tissue disorder that affects cardiovascular and musculoskeletal systems and the eye. ${ }^{1-3}$ Marfan syndrome has a high penetrance, but is characterised by strikingly heterogeneous inter- and intrafamilial phenotypes. ${ }^{3}$ In general, Marfan patients manifest some degree of cardiovascular, skeletal, and ocular involvement. However, in some cases, ocular signs, including bilaterial ectopia lentis, myopia, and retinal detachment clearly predominate as the major clinical feature.
Fibrillin is the principle structural element of a class of connective tissue microfibrils that have a widespread distribution. ${ }^{4-9}$ They are particularly abundant in tissues affected in Marfan syndrome, such as aorta, periosteum, ciliary zonules, the alveolar walls, and skin. Ultrastructural analyses have highlighted the complex architecture of fibrillin microfibrils. ${ }^{6810-12}$ They exhibit a pronounced beaded morphology with a diameter of 10 to $12 \mathrm{~nm}$ and an average, but variable, periodicity of $55 \mathrm{~nm}$. The mechanism of fibrillin assembly and microfibril organisation remains to be defined. The molecular complexity of fibrillin microfibrils was recently highlighted with the identification of a second fibrillin (FBN2) locus. ${ }^{13}$

Attempts have been made to relate genotype and phenotype as a means of understanding the pathogenesis of Marfan syndrome. Mutation analyses have identified more than thirty causative mutations in the FBN1 gene to date. ${ }^{114-26}$ Concurrently, biochemical analyses have highlighted variations between patient cells with respect to synthesis, secretion, and deposition of fibrillin..$^{27}$ However, there are still no satisfactory molecular explanations for how FBN 1 mutations influence microfibril assembly and functionality, and generate the disease phenotype.

We have previously used a combination of biochemical and ultrastructural approaches to investigate how different fibrillin mutations influence microfibril formation and organisation. ${ }^{2930}$ We have shown a range of microfibrillar abnormalities in a panel of Marfan patient cell lines and highlighted differences in fibrillin expression and aggregation between Marfan lines. In this study, we report the results of a similar strategy aimed at gaining insights into why certain fibrillin defects are particularly deleterious within the ocular system and predispose to lens dislocation. Using tissues and cells from two affected members of a three generation Marfan family, we have shown normal secretion and assembly of fibrillin but identified structurally and functionally abnormal microfibrils. In this case, the fibrillin defect which manifests at the macromolecular level clearly underlies their ocular symptoms.
Royal Eye Hospital,
Manchester M13 9WH,
UK
S J Charles
Correspondence to:
Dr Kielty.
Received 13 June 1994
Revised version accepted for
publication 1 September
1994

Royal Eye Hospital,
Manchester M13 9WH,
UK
S J Charles
Correspondence to:
Dr Kielty.
Received 13 June 1994
Revised version accepted for
publication 1 September
1994

Royal Eye Hospital,
Manchester M13 9WH,
UK
S J Charles
Correspondence to:
Dr Kielty.
Received 13 June 1994
Revised version accepted for
publication 1 September
1994

Royal Eye Hospital,
Manchester M13 9WH,
UK
S J Charles
Correspondence to:
Dr Kielty.
Received 13 June 1994
Revised version accepted for
publication 1 September
1994 
Material and methods

CLINICAL HISTORY

Ocular tissues and dermal fibroblasts were obtained from two affected cousins (ME and
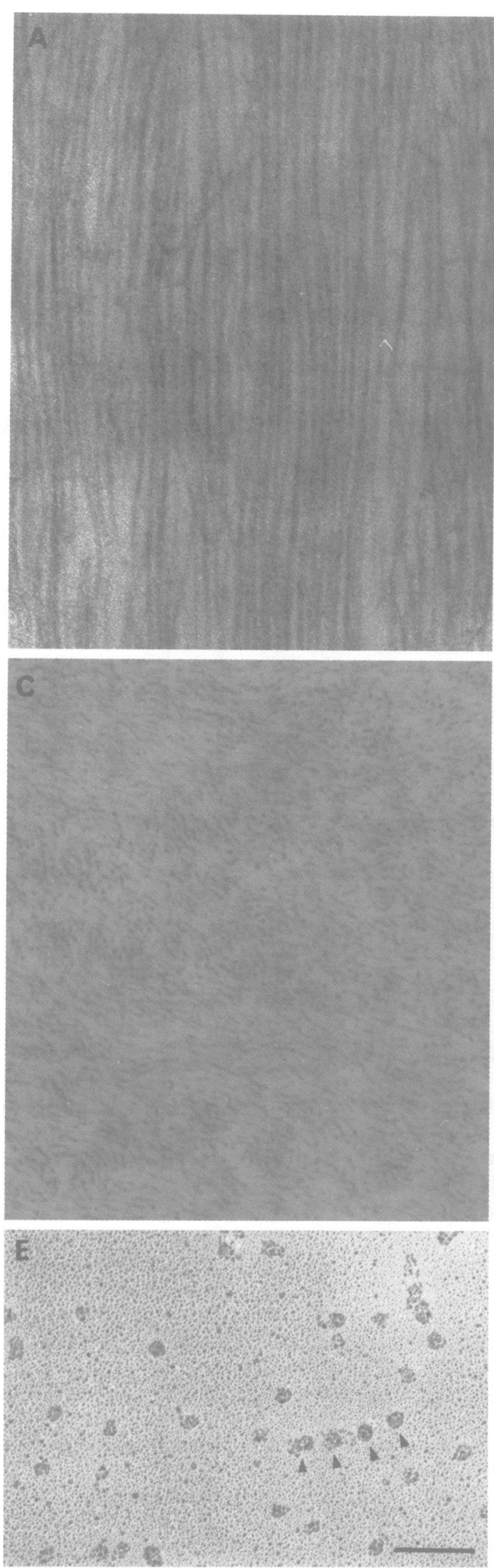

Figure 1 Ultrastructural analysis of ciliary zonules from patient $M E$ and control. Transmission electron micrographs of ciliary zonules from patient $M E(B, C)$ and control $(A, D)$. $(A)$ shows a control zonule in longitudinal section. $(B)$ shows a comparable section of patient zonule. ( $C$ and D) are cross sections through patient and control ciliary zonules. Rotary shadowing electron micrographs of microfibrils isolated from zonules of patient $M E(E)$ and control (F). Bars= $100 \mathrm{~nm}$.

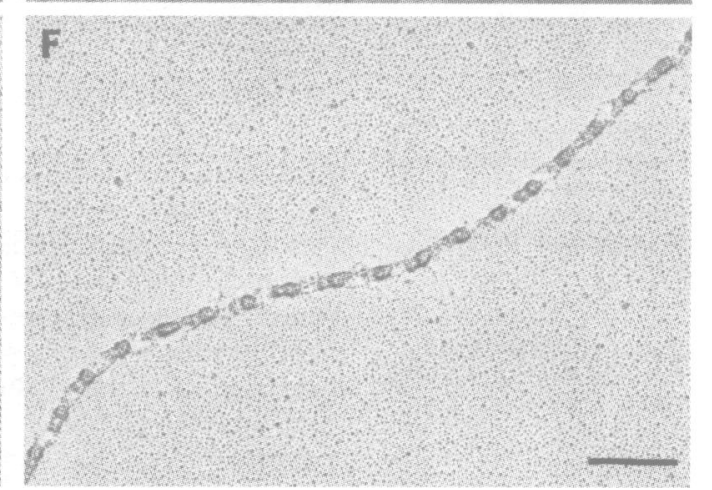

KC) of a three generation Marfan family. Both patients were tall with arachnodactyly and bilateral ectopia lentis, but valvular function and aortic root dimensions were normal by echo-
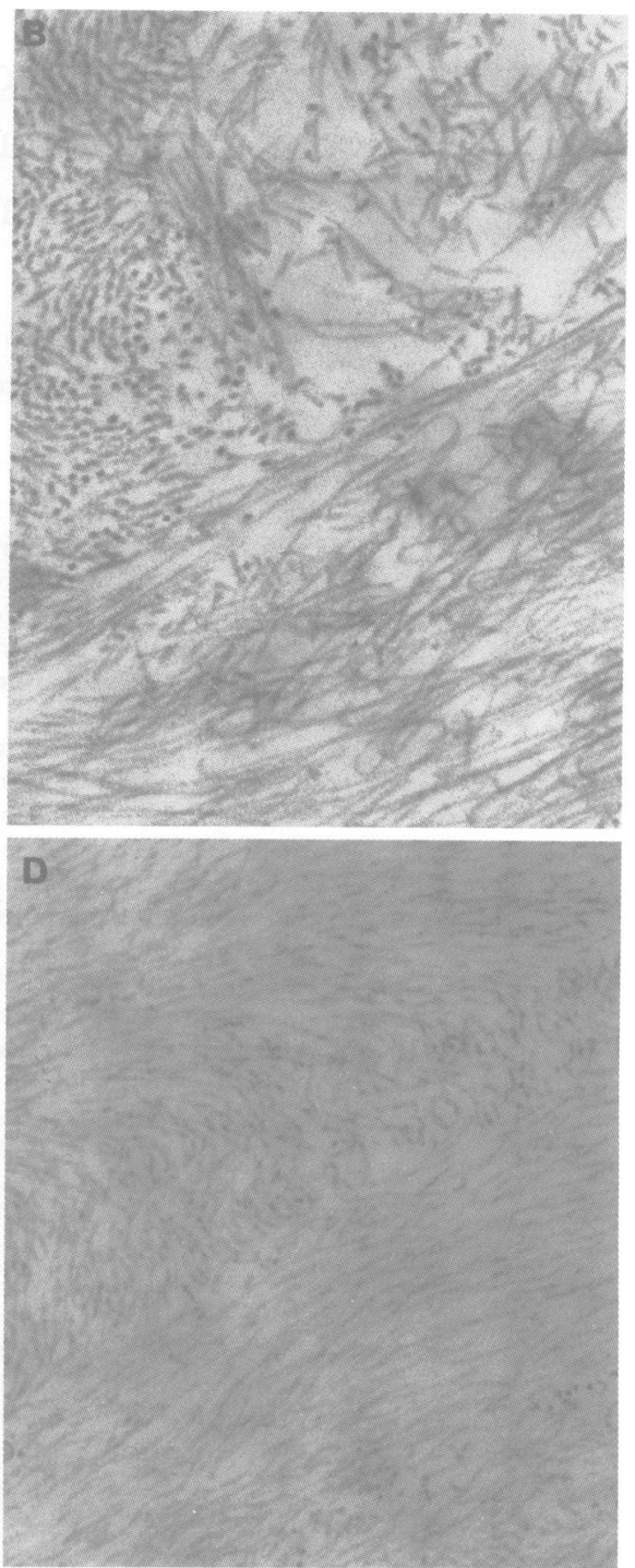

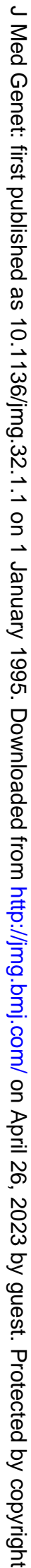


cardiography. A vitreolensectomy was performed for subluxed crystalline lens in patient ME. At surgery, lens capsule together with attached zonules were obtained for examination together with samples of anterior vitreous.

\section{TRANSMISSION ELECTRON MICROSCOPY}

Ciliary zonules and lens capsule removed at vitreolensectomy from $\mathrm{ME}$ were fixed with $3 \%$ glutaraldehyde in $0.1 \mathrm{~mol} / 1$ sodium cacodylate buffer ( $\mathrm{pH} \mathrm{7.4)}$ for four hours at room temperature, and washed three times over 24 hours in $0 \cdot 1 \mathrm{~mol} / 1$ sodium cacodylate buffer $(\mathrm{pH} 7 \cdot 4)$ containing $3 \mathrm{mmol} / 1 \mathrm{CaCl}_{2}$. Tissues were then carefully trimmed under a dissecting microscope before postfixation in $1 \%(\mathrm{w} / \mathrm{v})$ os- mium tetroxide in $0.5 \mathrm{~mol} / 1$ sodium cacodylate at $4^{\circ} \mathrm{C}$ for one hour, and briefly rinsed in buffer before dehydration in an ascending alcohol series. After incubation in two changes of polypropylene oxide, the tissue was infiltrated with TAAB epoxy resin (TAAB Laboratories Equipment Ltd, Aldermaston, UK) and placed in flat embedding moulds for polymerisation at $60^{\circ} \mathrm{C}$ for 72 hours. Sections $0 \cdot 5 \mu \mathrm{mol} / 1$ thick were cut on a Reichert OMUIII ultramicrotome and stained with $1 \%$ toluidine blue in $1 \%$ borax; appropriate areas were then selected for ultrathin sectioning. Pale gold (70 $\mathrm{nm}$ ) sections were mounted on copper grids and contrasted with uranyl acetate and lead citrate before examination in a Philips EM 301 electron microscope at an accelerating voltage of $60 \mathrm{kV}$. Control tissues were obtained from
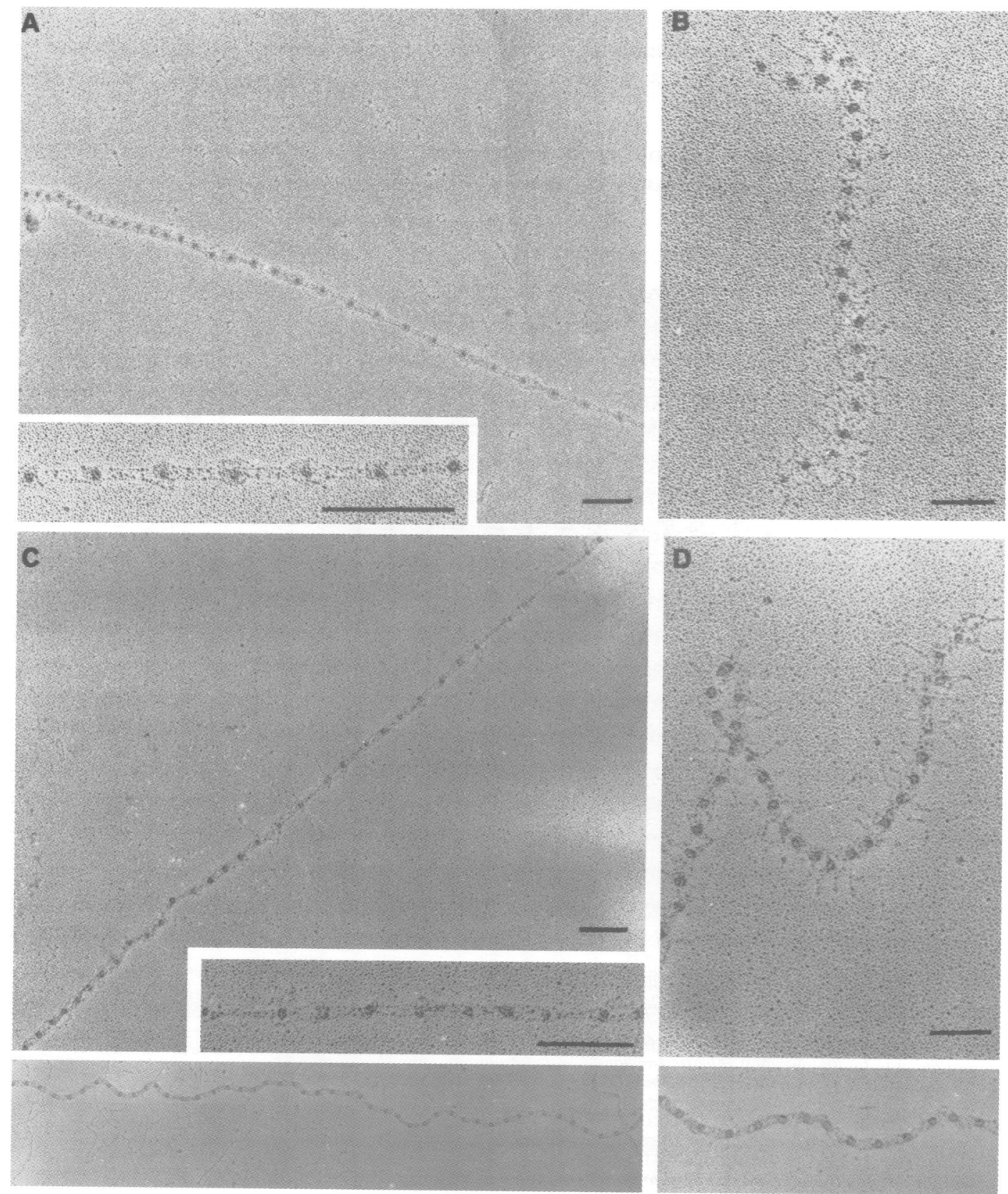

Figure 2 Rotary shadowing electron micrographs of microfibrils isolated from patient dermal fibroblast cell layers. ME and $K C$ cell lines elaborated abundant microfibrils. The predominant abnormality was irregular periodicity, with extended and contracted regions recurring within the same microfibrils $(C, E)$. In some fields, short microfibrillar arrays with a frayed appearance were also present $(D, F)$. ( $A$ and $B)$ microfibrils isolated from normal dermal fibroblasts; $(C$ and $D)$,
microfibrils isolated from $K C$ cultures; $(E$ and $F)$, microfibrils isolated from $M E$ cultures. Bars $=100 \mathrm{~nm}$. 
the Eye Bank at the Manchester Royal Eye Hospital.

ROTARY SHADOWING ELECTRON MICROSCOPY Tissue and cell layer preparations were visualised for their microfibril content by rotary shadowing electron microscopy using a modification of the mica sandwich technique. ${ }^{6}$ Samples visualised were void volume fractions of cell layer extracts (see below), ciliary zonules (from patient $\mathrm{ME}$ ) taken up and diluted in $0.5 \mathrm{~mol} / 1$ Tris $/ \mathrm{HCl}, \mathrm{pH} 7.4$ containing $0.4 \mathrm{~mol} / \mathrm{l} \mathrm{NaCl}, 2 \mathrm{mmol} / 1$ phenylmethanesulphonyl fluoride (PMSF), and $5 \mathrm{mmol} / \mathrm{l} \mathrm{N}$ ethyl maleimide (NEM), and vitreous (from patients $\mathrm{ME}$ and $\mathrm{KC}$ ) either neat or diluted $1: 1$ in the same buffer.

\section{CELLS AND CELL CULTURE}

Dermal fibroblast cultures were established by explant from skin biopsies obtained from $\mathrm{ME}$ and $\mathrm{KC}$, with the informed consent of both patients. Cells were routinely maintained in Dulbecco's minimum essential medium supplemented with $10 \%$ fetal calf serum, penicillin

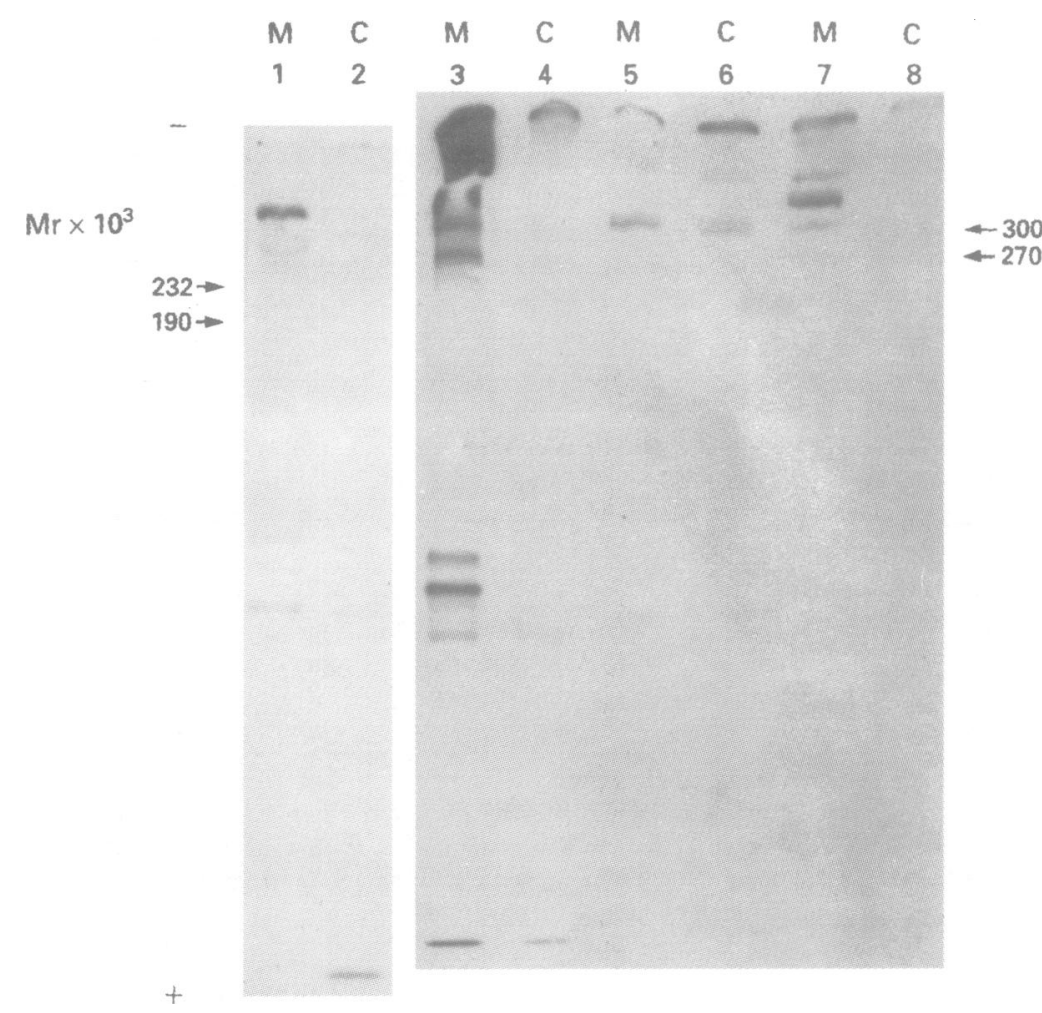

Figure 3 Electrophoretic analysis of fibrillin immunoprecipitated from medium and cell layer extracts of ME dermal fibroblasts. Cells were continuously labelled with $\left[{ }^{35} S\right]$ TranSlabel for 16 or 72 hours, or pulse labelled for 30 minutes and chased for two hours and 16 hours. Samples were analysed by SDS-PAGE on $8 \%$ gels under non-reducing conditions and by fluorography. The electrophoretic mobilities of molecular weight markers catalase $\left(M_{\mathrm{r}} 232000\right)$ and $\alpha 2-$ macroglobulin $\left(M_{\mathrm{r}} 190000\right)$ are indicated. Tracks 1,3 , 5 , and 7 , fibrillin immunoprecipitated from medium (M); tracks $2,4,6$, and 8 fibrillin immunoprecipitated from cell layer extracts $(C)$. When cells were continuously labelled for 16 or 72 hours there was evidence for several fibrillin immunoreactive components in medium $\left(M_{\mathrm{r}} \mathrm{s} 300000,270000\right.$, higher $M_{\mathrm{r}}$ aggregates and lower $M_{\mathrm{r}}$ components; tracks 1 and 3). Failure to detect labelled fibrillin in the cell layer extracts suggests that high $M_{\mathrm{r}}$ microfibrillar assemblies may be too large for effective immunoprecipitation (tracks 2 and 4). In the pulse chase experiment, after two hours secreted fibrillin $\left(M_{\mathrm{r}} 300000\right)$ was present as a doublet in medium after two hour chase (track 5) and in cell layers (track 6). After 16 hours chase, there was evidence for aggregation of fibrillin in medium (track 7), but again no detectable labelled fibrillin was immunoprecipitated from the cell layer extract (track 8).
( $400 \mathrm{U} / \mathrm{ml})$, streptomycin $(50 \mathrm{mg} / \mathrm{ml})$, and glutamine $(200 \mathrm{mg} / \mathrm{ml})$. Confluent cells were labelled with $\left[{ }^{35} \mathrm{~S}\right]$ TranSlabel in medium containing $0.5 \%$ fetal calf serum. (TRANS ${ }^{35}$ LABEL metabolic labelling reagent was supplied by ICN Biomedicals Ltd, Thame, Oxon, $\mathrm{UK}$. This reagent is derived from $\left[{ }^{35} \mathrm{~S}\right] \mathrm{E}$ coli hydrolysate and contains $70 \%$ L-methionine $\left[{ }^{35} \mathrm{~S}\right]$ and $20 \%$ L-cysteine $\left.\left[{ }^{35} \mathrm{~S}\right]\right)$. Proteinase inhibitors (2mmol/1 PMSF and $5 \mathrm{mmol} / \mathrm{l}$ NEM) were added after 16 hours. Cell layers were solubilised in $0.05 \mathrm{~mol} / 1 \mathrm{Tris} / \mathrm{HCl}, \mathrm{pH}$ 7.4 containing $0.4 \mathrm{~mol} / 1 \mathrm{NaCl}$ and $1 \%(\mathrm{v} / \mathrm{v})$ Nonidet P40 (NNT buffer). Fibrillin was immunoprecipitated from medium and cell layer compartments as previously described. ${ }^{730}$ In view of the similar electrophoretic mobilities on SDS-PAGE of fibronectin and fibrillin, fibronectin was removed before immunoprecipitation of fibrillin by two sequential

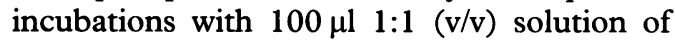
gelatine-Sepharose. Samples were then incubated for one hour at $20^{\circ} \mathrm{C}$ with a $1: 100$ dilution of a polyclonal fibrillin antiserum ${ }^{730}$ before the addition of $60 \mu \mathrm{l}$ of a $1: 1 \quad(\mathrm{v} / \mathrm{v})$ solution of protein A-Sepharose in NNT buffer.

For microfibril extractions, cells were maintained at post-confluence for up to three weeks. Cell layers were washed in $0.05 \mathrm{~mol} /$ 1 Tris $/ \mathrm{HCl}, \mathrm{pH} 7.4$ containing $0.4 \mathrm{~mol} / 1 \mathrm{NaCl}$ and $0.005 \mathrm{~mol} / 1 \mathrm{CaCl}_{2}$, then incubated for two hours at $20^{\circ} \mathrm{C}$ with $0 \cdot 1 \mathrm{mg} / \mathrm{ml}$ bacterial collagenase (type 1A), $2 \mathrm{mmol} / 1 \mathrm{PMSF}$ and $5 \mathrm{mmol} / 1 \mathrm{NEM}$. Soluble extracts were clarified by centrifugation for 15 minutes at $7500 \mathrm{~g}$ on a bench microfuge before size fractionation by gel filtration chromatography on Sepharose CL-2B. ${ }^{7}$

\section{Results}

OCULAR TISSUES

Transmission electron microscopy of ciliary zonules from patient $\mathrm{ME}$ showed the presence of abundant loose microfibril bundles (fig 1). In some fields, the microfibril bundles were markedly disrupted in comparison with those observed in the control tissue (fig 1A,B), and the patient microfibrils had apparently fragmented in places. In cross section, the organisation of some of these bundles appeared similar to the unaffected control (fig 1C,D).

When ciliary zonules from $\mathrm{ME}$ and a control were visualised by rotary shadowing

Distribution of counts incorporated into newly synthesised fibrillin by $K C$ and $M E$ cell lines

\begin{tabular}{llll}
\hline Cell line & $\begin{array}{c}\text { \% total incorporated } \\
\text { counts in fibrillin }\end{array}$ & \multicolumn{2}{c}{ Distribution of fibrillin (\%) in } \\
\cline { 3 - 4 } & & Medium & Cell layer \\
\hline KC & $0 \cdot 118$ & 39 & 61 \\
ME & $0 \cdot 109$ & 31 & 69 \\
Control & $0 \cdot 142$ & 36 & 64 \\
\hline
\end{tabular}

Cells were labelled for 16 hours with $\left[{ }^{35} \mathrm{~S}\right]$ TranSlabel. Fibrillin was immunoprecipitated from medium and cell layer extracts The amount of distribution of newly synthesised fibrillin was compared by determining the percentage of total immunofigures are averaged from two duplicate experiments. 
electron microscopy, it became apparent that extensive fragmentation had occurred in the patient sample (fig 1E,F). Very few intact microfibrils were observed, but there was evidence of numerous dissociated beaded domains. Visualisation of vitreous from $\mathrm{ME}$ and $\mathrm{KC}$ showed that, while fibrillin microfibrils were relatively scarce in this tissue, those present were also clearly disrupted (not shown).

\section{CELL CULTURES}

Dermal fibroblast cultures were established from both $\mathrm{ME}$ and $\mathrm{KC}$ in order to investigate these microfibrillar abnormalities further. Examination by rotary shadowing electron microscopy of high relative molecular mass material solubilised from postconfluent cell layers indicated that extensive and abundant microfibrils had been elaborated by control, $\mathrm{ME}$, and $\mathrm{KC}$ cultures (fig 2). The microfibrils present in control cultures were similar to those previously isolated from tissues and cells (fig $2 \mathrm{~A}, \mathrm{~B}) .^{67}$ In marked contrast, microfibrils extracted from $\mathrm{ME}$ and $\mathrm{KC}$ cell layers were abnormal in several morphological respects (fig 2C-F). In both cases, microfibrillar periodicity was markedly irregular along the microfibrils with areas of highly extended periodicity juxtaposed to contracted regions. In some cases, microfibrillar integrity had clearly been compromised within extended regions. While short microfibrillar arrays from both ME and KC both exhibited "fraying" in interbeaded domains, this was particularly apparent in the case of ME microfibrils. Furthermore, regions of KC microfibrils appeared poorly organised.

The expression and deposition of fibrillin in $\mathrm{ME}$ and $\mathrm{KC}$ dermal fibroblast cultures was investigated after 16 hours or pulse chase metabolic labelling and immunoprecipitation of fibrillin from medium and cell layer fractions. De novo fibrillin synthesis was expressed as total counts incorporated into fibrillin (table). The two lines synthesised comparable levels of fibrillin and in both cases the majority of newly synthesised fibrillin was deposited in the cell layer. Pulse chase experiments showed that fibrillin was present as a $M_{r}$ 300000 component which resolved as a doublet (fig 3). With time, some of this component became incorporated into higher $M_{r}$ aggregates. Interestingly, no monomers were detected in the cell layer at longer chase intervals. Continuous labelling highlighted a number of lower $M_{r}$ fibrillin immunoreactive bands in the medium. The presence of these bands suggests that a portion of the newly synthesised fibrillin is catabolised and does not contribute to the formation of stable fibrillin aggregates.

\section{Discussion}

The relationship between defined mutations in FBN1, fibrillin defects, and clinical phenotype remains largely obscure despite the documentation of more than thirty mutations to date and the demonstration of a range of defects in the expression and assembly of fibrillin. ${ }^{14-262930}$ The complexity of the disease is highlighted by the strikingly heterogeneous inter- and intrafamilial phenotypes, and to date no molecular explanation for this phenomenon has emerged. In this study, we have investigated the relationship between defined microfibrillar abnormalities and clinical symptons in a family whose affected members consistently manifest lens dislocation and skeletal symptoms, but who have no cardiovascular involvement.

Direct ultrastructural examination of patient ciliary zonules confirmed the presence of abundant loose microfibril bundles, and provided evidence for disrupted zonule organisation and fragmentation of microfibrils. When patient ciliary zonules and vitreous were examined by rotary shadowing electron microscopy, it was immediately apparent that the microfibrils were comprehensively fragmented. In order to investigate these abnormal microfibrillar assemblies further, we carried out a biochemical and ultrastructural analysis of fibrillin expression and assembly by patient dermal fibroblasts. These studies established that the pattern of fibrillin secretion and deposition was normal but highlighted that not all the newly synthesised fibrillin was effectively incorporated into high $M_{r}$ aggregates. Furthermore, the presence of low $M_{r}$ fibrillin immunoreactive components was suggestive of increased turnover in medium and cell layers. The resolution of fibrillin as a doublet has previously been reported for several other cell lines and taken as indicative of a putative processing event. ${ }^{2731}$ The ultrastructural observation that abundant microfibrils had been laid down by both cell lines confirmed that ordered assenibly of fibrillin had occurred. However, a striking abnormal feature of the microfibrils elaborated by both cell lines was their highly irregular periodicity and evidence for substantial fragmentation within extended regions.

Our results show conclusively that fibrillin microfibrils in these tissues are structurally and functionally abnormal. In view of the exclusively microfibrillar composition of the ciliary zonules, it appears likely that, in these patients, the microfibrils are unable to sustain their role in the dynamic suspension of the lens. In Marfan syndrome it is thought that ectopia lentis results from laxity of the zonular fibres since a good zonular complement is often observed in the area of dislocation. ${ }^{32}$ Interestingly, ultrastructural analyses have suggested that normal fibrillin microfibrils possess the capacity to extend and retract. ${ }^{8}$ In this study, we have shown markedly variable periodicity within isolated microfibrils suggesting that the normal molecular mechanism for sustaining microfibrillar periodicity is compromised in these patients.

Essentially normal function of the elastic tissues of these patients suggests that the capacity of their microfibrils to interact with elastin has not been affected by the causative mutation. It is interesting to speculate that 
the preferential expression of a second fibrillin locus (FBN2) in elastic tissues may in fact compensate for defective FBN1 in these patients. The role of fibrillin in bone, and the influence of microfibrillar abnormalities on the skeletal systems of these patients remain to be defined.

This is the first direct correlation of microfibrillar abnormalities manifest by patient cell cultures and tissues. Future studies will be directed to the association of defined mutations with ultrastructural abnormalities.

This work was supported by the Medical Research Council and the Arthritis and Rheumatism Council. The author thank Professor D McLeod for his help in this project.

1 Lee B, Godfrey M, Vitale E, et al. Linkage of Marfan syndrome and a phenotypically related disorder to two different fibrillin genes. Nature 1991;352:330-4.

2 Tsipouras $\mathrm{P}$, Del Mastro $\mathrm{R}$, Sarfarazi $\mathbf{M}$, et al. Linkage analysis demonstrates that Marfan syndrome, dominan ectopia lentis and congenital contractural arachnodactyly are linked to the fibrillin genes on chromosomes 15 and 5. N Engl f Med 1992;326:905-9.

3 Pyeritz RE. The Marfan syndrome. In: Royce PM, Steinmann B, eds. Connective tissue and its

disorders. New York: Wiley-Liss, 1993:437-67.

Sakai LY, Kenne DR, Engvall E. Fibrillin, a new 350 $\mathrm{kD}$ glycoprotein, is a component of ex

5 Sakai LY, Keene DR, Glanville RW, Bachinger HP. Purification and partial characterisation of fibrillin, a cysteine-rich structural component of connective tissue cysteine-rich structural component of connective

6 Kicrofibrils. Fummings C, Whittaker SP, Shuttleworth Cielty CM, Cummings CA, Grant ME. Isolation and ultrastructural antic tissues. microflibrillar structures from

7 Kielty CM, Berry L, Whittaker SP, Grant ME, ShuttleKielty CM, Berry L, Whittaker SP, Grant $\mathrm{ME}$, Shutdeworth CA. Microfibrillar as

8 Keene DR, Maddox BK, Kuo HJ, Sakai LY, Glanville RW. Extraction of extendable beaded structures and their identification extendable beaded structures and microfibrils. $\mathcal{f}$ Histochem Cytochem 1991;39:441-9.

9 Wallace RN, Streeten BW, Hanna RB. Rotary shadowing of elastic system microfibrils in the ocular zonule, vitreous and ligamentum nuchae. Curr Eye Res 1991 vitreous and 109 .

10 Wright DW, Mayne R. Vitreous humor of chicken contain two fibrillar systems: an analysis of their structure. Ultrastruct Molec Struct Res 1988;100:224-34.

11 Wright DW, McDaniels CN, Swasdison S, Accavitti MA Mayne PM, Mayne R. Immunization with undenatured bovine zonular fibrils results in monoclonal antibodies to fibrillin. Matrix Biol 1994;14: 41-9.

12 Fleischmajer R, Contard P, Schwartz E, MacDonald ED, Jajer R, Contar ED, Jabobs $\mathrm{L}$, Sakai LY. Elast fibroblast culture. f Invest Dermatol 1991;97:639-43.

13 Zhang $\mathrm{H}$, Apfelroth $\mathrm{SD}, \mathrm{Hu} \mathrm{W}$, et al. Structure and expression of fibrillin-2, a novel microbfibrillar com- ponent preferentially located in elastic matrices. $\mathcal{F}$ Cell Biol 1994;124:855-63.

14 Dietz HC, Cutting GR, Pyeritz RE, et al. Marfan syndrome caused by a recurrent de novo missense mutation in the fibrillin gene. Nature 1991;352:337-9.

15 Dietz HC, Saraiva JM, Pyeritz RE, Cutting GR, Francomano CA. Clustering of fibrillin (FBN1) missense mutations in Marfan syndrome patients at cysteine residues in EGF-like domains. Hum Mutat 1992;1: 366-74.

16 Dietz HC, Pyeritz RE, Puffenberger EG, et al. Marfan phenotype variability in a family segregating a missense the fibrillin gene. $尹$ Clin Invest 1992;89:1674-80.

17 Dietz HC, Valle D, Francomano CA, Kendzior RJ, Pyeritz RE, Cutting GR. The skipping of constitutive exons in RE, Cutting GR. The skipping of constitutive exons in $680-3$.

18 Dietz HC, McIntosh I, Sakai LY, et al. Four novel FBN1 mutations: significance for mutant transcript level and mutations: significance for mutant transcript level and Ef Marfan syndrome. Genomics 1993;17:468-75.

19 Kainulainen K, Peltonen L. Marfan syndrome: molecular pathogenesis. Adv Genome Biol 1994;2:113-33.

20 pathogenesis. Aavai LY, Child AH, et al. Two mutations in Marfan syndrome resulting in truncated fibrillin in Marfan syndrome resulting in truncated fibrillin

polypeptides. Proc Natl Acad Sci USA 1992;89:5917-21.
21 Kainulainen K, Kartunnen K, Puhakka L, Sakai LY, Peltonen L. Mutations in the fibrillin gene responsible for dominant ectopia lentis and neonatal Marfan syndrome. Nature Genet 1994;6:64-9.

22 Godfrey $M$, Vandemark N, Wang $M$, et al. Prenatal diagnosis and a donar splice site mutation in fibrillin in a family with Marfan syndrome. Am $\mathcal{f}$ Hum Gene 1993;49:662-7.

23 Hewitt DR, Lynch JR, Smith R, Sykes B. A novel fibrillin mutation in the Marfan syndrome which could disrup calcium binding of the epidermal growth factor-like module. Hum Molec Genet 1993;2:475-7.

24 Tynan K, Comeau K, Pearson M, et al. Mutation screening of complete fibrillin-1 coding sequence: report of five new mutations, including two in 8-cysteine domains. Hum Molec Genet 1993;2:1813-21.

25 Hayward C, Porteous MEM, Brock DJH. Identification of a novel nonsense mutation in the fibrillin gene (FBN1) using nonisotopic techniques. Hum Mutat 1994 3:159-62.

26 Milewicz DM, Duvic M. Severe neonatal Marfan syndrome resulting from a de novo 3-bp insertion into the fibrillin resulting from a de nov 15 Am $\mathcal{F}$ Hum Genet 1994:54: gene on

27 McGookey Milewicz D, Pyeritz RE, Crawford ES, Byer PH. Marfan syndrome: defective synthesis, secretion PH. Marfan syndrome: defective synthesis, secretion and extracellular matrix fin Invest. 1992;89:79-86.

28 Arma The U, Furthmayr Aoyama T, Tynan K, Dietz HC, Francke U, Furthmayr H. Missense mutations impair intracellular processing Hum Molec Genet 1994;2:2135-40.

29 Kielty CM, Shuttleworth CA. Abnormal fibrillin assembly Kielty CM, Shuttleworth CA. Abnormal fibrillin assembly by dermal fibroblasts from two patients

30 Kielty CM, Phillips JE, Child AH, Pope FM, Shuttleworth CA. Fibrillin secretion and microfibril assembly by Marfan dermal fibroblants. Matrix Biol 1994;14:191-9. 31 Ragn B. Decreased deposition of fibrillin and decorin in neonatal Marfan syndrome fibroblasts. Hum Genet 1993; 90:5411-15.

32 Nelson LB Maumanee IH. Ectopia lentis. Surv Ophthalmol $986 ; 27: 143-60$ 